This work is licensed under a Creative Commons Attribution License (CC BY 4.0).

Research article

urn:lsid:zoobank.org:pub:9B4AFA0E-3805-405C-AB6B-4D61E1875855

\title{
First record of the genus Augilina Melichar, 1914 (Hemiptera, Fulgoromorpha, Caliscelidae) from China, with descriptions of two new bamboo-feeding species
}

\author{
Nian GONG ${ }^{\circledR 1}$, Lin YANG ${ }^{\circledR 2}$ \& Xiang-Sheng CHEN ${ }^{\circledR 3, *}$ \\ 1,2,3 Institute of Entomology, Guizhou University, the Provincial Special Key Laboratory for \\ Development and Utilization of Insect Resources, Guiyang, Guizhou, 550025, P.R. China. \\ *Corresponding author: chenxs3218@163.com \\ ${ }^{1}$ Email: gongn0921@foxmail.com \\ 2Email: yanglin6626@163.com \\ ${ }^{1}$ urn:1sid:zoobank.org:author:3D0525A2-EBBC-4734-929C-710FD0DFA8A6 \\ ${ }^{2}$ urn:1sid:zoobank.org:author:17FAF564-8FDA-4303-8848-346AB8EB7DE4 \\ ${ }^{3}$ urn:1sid:zoobank.org:author:D9953BEB-30E6-464A-86F2-F325EA2E4B7C
}

\begin{abstract}
The planthopper genus Augilina Melichar, 1914, is recorded in China for the first time. Two new species of the genus Augilina, A. tetraina Chen \& Gong sp. nov. and A. triaina Chen \& Gong sp. nov., are described and illustrated from South China. The genus now has a total of four described species. New generic characteristics are proposed and photographs of the new species are provided. A checklist and a key to the species of Augilina are also included.
\end{abstract}

Keywords. Augilini, Ommatidiotinae, taxonomy, South China, bamboo.

Gong N., Yang L. \& Chen X.S. 2021. First record of the genus Augilina Melichar, 1914 (Hemiptera, Fulgoromorpha, Caliscelidae) from China, with descriptions of two new bamboo-feeding species. European Journal of Taxonomy 744: 38-48. https://doi.org/10.5852/ejt.2021.744.1297

\section{Introduction}

The caliscelid genus Augilina Melichar, 1914, described by Melichar (1914) based on a single species, Augilina longipes Melichar, 1914, from the Philippines (Luzon Island), belongs to the tribe Augilini of the subfamily Ommatidiotinae (Hemiptera: Fulgoroidea: Caliscelidae) (Emeljanov 1999; Gnezdilov 2013a). Recently, Gnezdilov (2013b) added the second species, Augilina namboina Gnezdilov, 2013, from southern Vietnam. Here, the genus Augilina is recorded in China for the first time with two new species, A. tetraina Chen \& Gong sp. nov. and A. triaina Chen \& Gong sp. nov., discovered on bamboo in Yunnan Province. Their descriptions and illustrations are given. New generic characteristics are proposed. A checklist and a key to the species of Augilina are provided. 


\title{
Material and methods
}

The morphological terminology used in this study mainly follows Chan \& Yang (1994) and Gnezdilov (2013b). The standard terminology for hind and forewing venation follows Bourgoin et al. (2015). Dry specimens were used for the descriptions and illustrations. External morphology was observed under a stereo microscope and characters were measured with an ocular micrometer. Measurements are given in millimeters; body length was measured from the apex of the head to the apex of the forewing in repose. The genital segments of the examined specimens were macerated in $10 \% \mathrm{NaOH}$, washed in water, and transferred to glycerin. Illustrations of the specimens were made with a Leica MZ 12.5 stereo microscope. Photographs were taken with a KEYENCE VHX-1000 system. Illustrations were scanned with CanoScan LiDE 200 and imported into Adobe Photoshop CS7 for labeling and plate composition.

The type specimens and material examined are deposited in the Institute of Entomology, Guizhou University, Guiyang, China (IEGU).

\section{Results}

\section{Taxonomy}

\author{
Class Insecta Linnaeus, 1758 \\ Order Hemiptera Linnaeus, 1758 \\ Suborder Fulgoromorpha Evans, 1946 \\ Family Caliscelidae Amyot \& Serville, 1843 \\ Subfamily Ommatidiotinae Fieber, 1875 \\ Tribe Augilini Backer, 1915
}

Genus Augilina Melichar, 1914

Figs 1-34

Augilina Melichar, 1914: 276.

Augilina - Gnezdilov 2013b: 171.

\section{Type species}

Augilina longipes Melichar, 1914.

\section{Diagnosis}

Vertex long and narrow, strongly produced anteriorly, posterior margin angularly concave, disc depressed. Frons long and narrow, with median and sublateral carinae, widest at level of second segment of antennae. Ocelli present. Pronotum with anterior margin strongly convex, posterior margin broadly concave; lateral carinae converging apically. Mesonotum large, almost 3 times as long as pronotum, disc flattened. Forewing long, narrow, transparent. Hindwing transparent, longer than half length of forewing. Legs relatively long, hind tibia with single lateral spine medially and with 6 apical spines. First and second metatarsomeres with no spines. Abdomen exceptionally elongate and narrow, sternites chevron-shaped. Male genitalia: anal tube short, enlarged apically. Pygofer in lateral view with dorsal half much narrower than ventral half, hind margin of pygofer concaved at upper $2 / 3$, lower $1 / 3$ almost straight; in posterior view, ventral margin with two rounded medioventral processes. Genital styles massive, each with 3-4 processes. Aedeagus of simple structure, with enlarged basement and narrow tubular-shaped apical part. Gonopore subapical. 


\section{Distribution}

Philippines (Luzon), southern Vietnam, southern China.

\section{Remark}

Compared with Melichar's (1914) description, we propose more concise generic characteristics based on the comparison of four species, and add the generic characteristics of the male genitalia.

\section{Checklist of species of Augilina Melichar, 1914}

A. longipes Melichar, 1914; Philippines (Luzon).

A. namboina Gnezdilov, 2013; Vietnam (Dong Nai Province).

A. tetraina Chen \& Gong sp. nov.; China (Yunnan Province).

A. triaina Chen \& Gong sp. nov.; China (Yunnan Province).

\section{Key to species of genus Augilina}

1. Forewing with wide dark brown band before the nodal line (Melichar 1914: fig. 8b)

A. longipes Melichar, 1914

- Forewing without band 2

2. Posterior margin of pygofer in lateral view without finger-like process near its dorsal margin (Gnezdilov 2013: fig. 15) A. namboina Gnezdilov, 2013

- Posterior margin of pygofer in lateral view with one finger-like process near its dorsal margin ..... 3

3. Genital styles with 4 processes (Fig. 12) A. tetraina Chen \& Gong sp. nov.

- Genital styles with 3 processes (Fig. 26) A. triaina Chen \& Gong sp. nov.

Augilina longipes Melichar, 1914

Augilina longipes Melichar, 1914: 276, fig. 8.

Augilina longipes - Che et al. 2009: 51, figs 4-6. — Gnezdilov 2013: 172, figs 1-2.

\section{Distribution}

Philippines, Luzon (Fig. 35).

\section{Remarks}

Based on the description and the figures by Melichar (1914), A. longipes closely resembles A. namboina Gnezdilov, 2013, but can be distinguished from the latter by the following characters: 1) pronotum whitish, mesonotum dark brown or black (vs pro- and mesonotum light green yellowish, with median red stripe framed by two black stripes in A. namboina);2) forewing with wide dark brown band before the nodal line (vs without band in A. namboina); 3) femora and tibiae brown or dark brown (vs light green yellowish in A. namboina).

\section{Augilina namboina Gnezdilov, 2013}

Augilina namboina Gnezdilov, 2013b: 172-175, figs 3-7, 11-12, 15-17.

\section{Distribution}

Vietnam, Dong Nai Province (Fig. 35). 


\section{Remarks}

Based on the description and the figures by Gnezdilov (2013b), this species can be distinguished from the other species of the genus by the following characters: body mainly light brown; pro- and mesonotum light green yellowish, with median red stripe framed by two black stripes; pygofer in lateral view, with posterior margin sinuated without process.

Augilina tetraina Chen \& Gong sp. nov.

urn:1sid:zoobank.org:act:435849B6-4C72-4317-B035-1D6245751FFD

Figs 1-14

\section{Diagnosis}

Posterior margin of pygofer in lateral view with one finger-like process dorsally (Fig. 9); posterior margin of pygofer with two small medioventral processes (Figs 10, 12); anal style small (Figs 8-9); aedeagus broadly concave in apical half (Fig. 13); genital styles with four processes (Figs 11-12).

\section{Etymology}

The specific name is derived from the Latin word 'tetra' which refers to the genital styles with four processes.

\section{Material examined}

\section{Holotype}

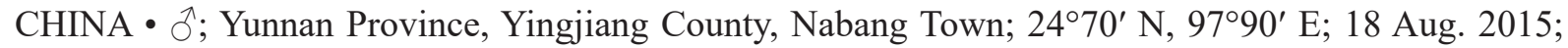
Xiang-Sheng Chen leg.; on bamboo; IEGU.

\section{Paratypes}

CHINA • $2 \widehat{\partial} \widehat{\jmath}$; same collection data as for holotype; Lin Yang leg.; IEGU.

\section{Description}

Measurements. Body length including forewing: male 6.7-6.8 $\mathrm{mm}(\mathrm{N}=3)$; forewing length: male $5.4 \mathrm{~mm}(\mathrm{~N}=3)$.

Coloration (in alcohol). Body mainly yellow (Figs 1-5). Eyes yellowish brown. Antennae with one black spot at apex of pedicel. Central area of vertex yellowish brown. Pronotum and mesonotum with wide median light red stripe. Spines of legs with black apices.

Head and thorax. Vertex including eyes 0.8 times width of pronotum. Vertex (Fig. 3) longer in middle line than broad at widest part (2.62:1). Frons (Fig. 4) 2.97 times as long as middle line at widest part. Pronotum (Fig. 3) shorter in middle line than vertex (1:2.59). Mesonotum (Fig. 3) 0.7 times as long as vertex and pronotum together in middle line. Forewing (Fig. 6) longer in middle line than broad at widest part (4.95:1); veins visible, with nodal line, $\mathrm{R}$ and MP with common stem, $\mathrm{R}$ with 3 branches before nodal line; after nodal line, R single, MP with five branches, $\mathrm{CuA}$ with two branches, Pcu uniting A1 at basal third of clavus. Hindwing (Fig. 7) 2.22 times as long as broad at widest part, ScP and RP single, MP and $\mathrm{CuA}$ with two branches.

Male Genitalia. Anal segment in dorsal view (Fig. 8), 2 times as long as middle line at widest part, broadening apically, broadest at apical third; in lateral view (Fig. 9), dorsal margin slightly concave, ventral margin slightly concave. Anal style small (Fig. 8). Pygofer in lateral view (Fig. 9), posterior margin with one finger-like process dorsally, upper $2 / 3$ concave, lower $1 / 3$ almost straight; in posterior view (Fig. 10), nearly oval, 1.5 times as long as widest part; in ventral view (Fig. 12), posterior margin 


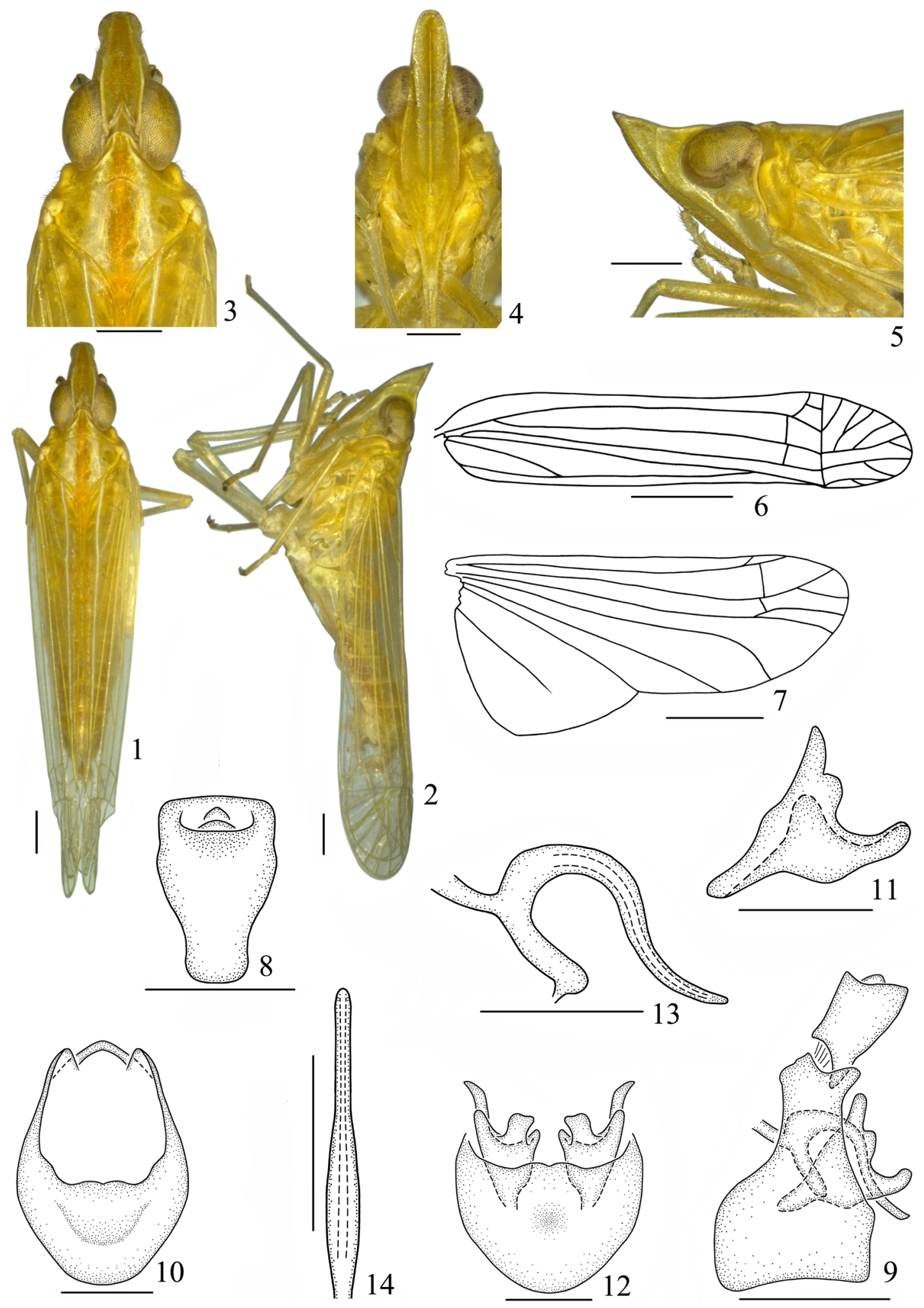

Figs 1-14. A. tetraina Chen \& Gong sp. nov., $\widehat{~}$ (holotype, IEGU). 1. Habitus, dorsal view. 2. Habitus, lateral view. 3. Head and thorax, dorsal view. 4. Face. 5. Head and thorax, lateral view. 6. Forewing. 7. Hindwing. 8. Anal segment, dorsal view. 9. Male genitalia, lateral view. 10. Pygofer, posterior view. 11. Genital styles, lateral view. 12. Pygofer and genital styles, ventral view. 13. Aedeagus, lateral view. 14. Aedeagus, dorsal view. Scale bars: $1-5,9=0.5 \mathrm{~mm} ; 6-7=1 \mathrm{~mm} ; 8,10-14=0.3 \mathrm{~mm}$. 
with two short and broad medioventral processes, anterior margin convex. Genital styles (Figs 11-12) with median portion broad, large, each with four processes, 2.2 times as long as widest part. Aedeagus (Figs 13-14) tubular, slender and long, tapering apically, in lateral view, strongly curved to the basement, apical half broadly concave.

\title{
Host plant
}

Bamboo.

\section{Distribution}

China (Yunnan) (Fig. 35).

\section{Remarks}

This new species is similar to A. namboina, but differs in: 1) pygofer in lateral view, posterior margin with one finger-like process near dorsal margin (vs without in A. namboina); 2) aedeagus broadly concave posteriorly on apical half (vs almost straight in A. namboina); 3) pygofer in ventral view, posterior margin with two small medioventral processes (vs relatively large medioventral processes in A. namboina).

\author{
Augilina triaina Chen \& Gong sp. nov. \\ urn:1sid:zoobank.org:act:29E0419B-44A4-4E5E-9564-68F121C74002
}

Figs 15-34

\section{Diagnosis}

Posterior margin of pygofer in lateral view with one finger-like process dorsally (Fig. 23); posterior margin of pygofer with two small medioventral processes (Figs 24, 26); anal style large (Figs 22-23); aedeagus with almost straight in apical half (Fig. 27); genital styles with three processes (Figs 25-26).

\section{Etymology}

The specific name is derived from the Latin word 'triaina' which refers to the genital styles with three processes.

\section{Material examined}

\section{Holotype}

CHINA • $\mathrm{O}^{\top}$; Yunnan Province, Jinghong City, Menglong Town; $21^{\circ} 58^{\prime} \mathrm{N}, 100^{\circ} 68^{\prime} \mathrm{E}$; 23 Jun. 2019; Nian Gong leg.; on bamboo; IEGU.

\section{Paratypes}

CHINA $・ 15 \widehat{\jmath}, 24$ + $\odot$; same collection data as for holotype; Hongxing Li, Fenge Li and Shiyan Xu leg.; IEGU • 1 ô, 2 ᄋ; Yunnan Province, Mengla County, Menglun Town; $21^{\circ} 50^{\prime} \mathrm{N}, 101^{\circ} 00^{\prime} \mathrm{E} ; 27 \mathrm{Jul}$. 2013, Yuan Liu leg.; on bamboo; IEGU.

\section{Description}

MEASUREMENTS. Body length including forewing: male 6.1-6.4 $\mathrm{mm}(\mathrm{N}=3)$; forewing length: male $5.1-5.3 \mathrm{~mm}(\mathrm{~N}=3)$.

Coloration. Body mainly yellowish green (Figs 15-19). Eyes taupe. Antennae with one black spot at apex of pedicel. Pronotum and mesonotum with wide median light red stripe. Spines of legs with black apices. 

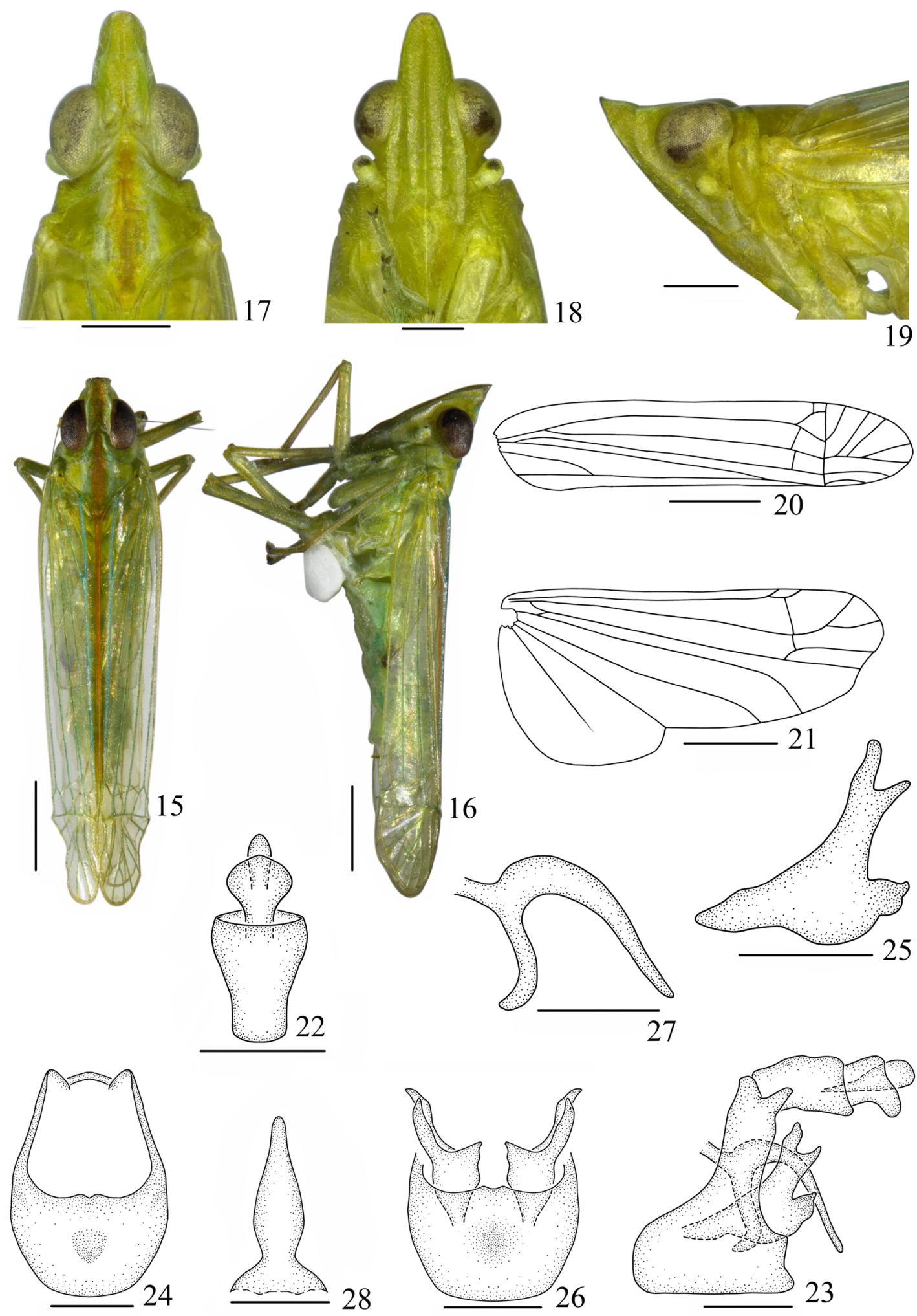

Figs 15-28. A. triaina Chen \& Gong sp. nov., ô (holotype, IEGU). 15. Habitus, dorsal view. 16. Habitus, lateral view. 17. Head and thorax, dorsal view. 18. Face. 19. Head and thorax, lateral view. 20. Forewing. 21. Hindwing. 22. Anal segment, dorsal view. 23. Male genitalia, lateral view. 24. Pygofer, posterior view. 25. Genital styles, lateral view. 26. Pygofer and genital styles, ventral view. 27. Aedeagus, lateral view. 28. Aedeagus, dorsal view. Scale bars: $15-16,20-21=1 \mathrm{~mm} ; 17-19=0.5 \mathrm{~mm} ; 22-28=0.3 \mathrm{~mm}$. 
Head and thorax. Vertex including eyes as wide as pronotum. Vertex (Fig. 17) longer in middle line than broad at widest part (2.3:1). Frons (Fig. 18) 2.4 times as long as middle line at widest part. Pronotum (Fig. 17) shorter in middle line than vertex (1:2.5). Mesonotum (Fig. 17) 0.8 times as long as vertex and pronotum together in middle line. Forewing (Fig. 20) longer in middle line than broad at widest part (4.9:1); veins visible, with nodal line, $\mathrm{R}$ and MP with common stem, $\mathrm{R}$ with 3 branches before nodal line; after nodal line, $\mathrm{R}$ single, MP with four branches, CuA single, Pcu uniting A1 at basal third of clavus. Hindwing (Fig. 21) 2.12 times as long as broad at widest part, ScP and RP single, MP and CuA with two branches.

Male Genitalia. Anal segment in dorsal view (Fig. 22), 1.4 times as long as middle line at widest part, broadening apically, broadest at apex; in lateral view (Fig. 23), dorsal margin slightly convex, ventral margin slightly concave. Anal style large (Fig. 22). Posterior margin of pygofer in lateral view (Fig. 23) with one finger-like process dorsally, upper $2 / 3$ concave, lower $1 / 3$ almost straight, base convex; in posterior view (Fig. 24), nearly oval, 1.4 times as long as widest part; posterior margin in ventral view (Fig. 26), with two short and small medioventral processes, anterior margin almost straight. Genital styles (Figs 25-26) with median portion broad, large, each with three processes, 2.7 times as long as widest part. Aedeagus (Figs 27-28) tubular, slender and long, tapering apically, in lateral view, strongly curved to the basement, with almost straight apical half.

Female Genitalia. Abdominal sternite VII (Figs 30, 32) in ventral view symmetrical, posterior margin concave, with a medioventral process. Anal tube (Figs 29, 31) short. Gonapophysis VIII (first valvula) (Fig. 33) elongate, with six spines at apical margin. Gonapophysis IX (second valvula) (Fig. 34) with
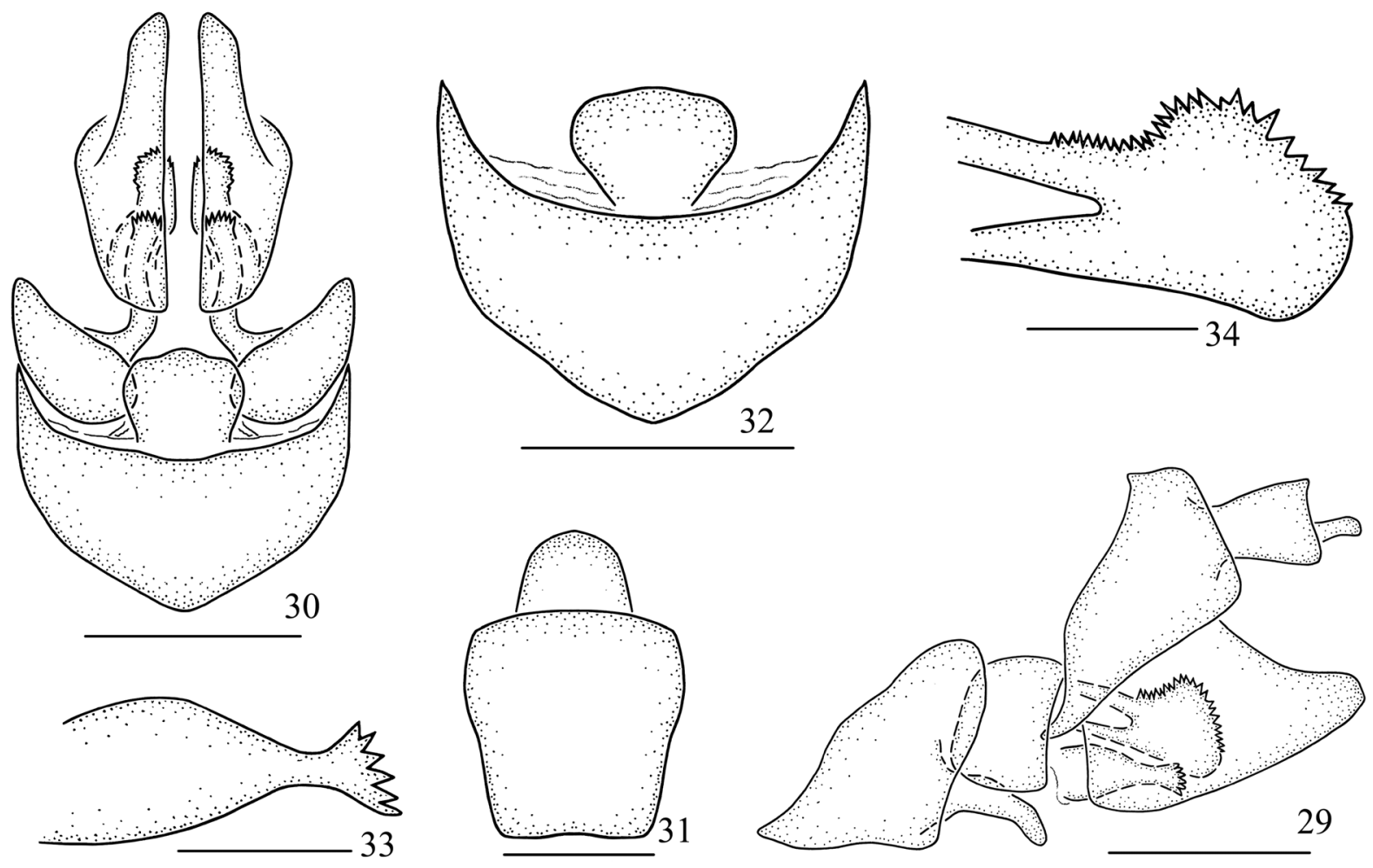

Figs 29-34. A. triaina Chen \& Gong sp. nov., $q$ (paratype, IEGU). 29. Genitalia, lateral view. 30. Genitalia, ventral view. 31. Anal segment, dorsal view. 32. Abdominal sternite VII, ventral view. 33. Gonapophysis VIII, lateral view. 34. Gonapophysis IX, lateral view. Scale bars: 29-30, $32=0.5 \mathrm{~mm}$; $31,33-34=0.2 \mathrm{~mm}$. 
two symmetrical lobes, each lobe with many spines at apical margin and dorsal margin. Gonoplac (third valvula) with outer surface shagreen (Figs 29-30); in lateral view (Fig. 29) with median portion broad, large, apical margin convex; in ventral view (Fig. 30) blade-like.

\section{Host plant}

Bamboo (Fig. 36).

\section{Distribution}

China (Yunnan) (Fig. 35).

\section{Remarks}

This new species is similar to A. tetraina sp. nov., but differs in: 1) anal style large (vs small in A. tetraina sp. nov.); 2) aedeagus with almost straight apical half (vs broadly concave in A.tetraina sp. nov.); 3 ) genital styles with three processes (vs with four processes in A. tetraina sp. nov.).

\section{Discussion}

The genus Augilina is recorded for the first time from China. It is closely related to Symplana Kirby, 1891, but can be distinguished from the latter as follows (after Gnezdilov 2013b): 1) in dorsal view (Gnezdilov 2013b: figs 5, 8), the vertex is narrow basally (vs wide in Symplana); 2) in lateral view (Gnezdilov 2013b: figs 6, 9), the apex of vertex is strongly curved (vs weakly curved in Symplana); 3 ) the forewing (Gnezdilov 2013b: figs 11,13) is widely rounded apically (vs narrow in Symplana).

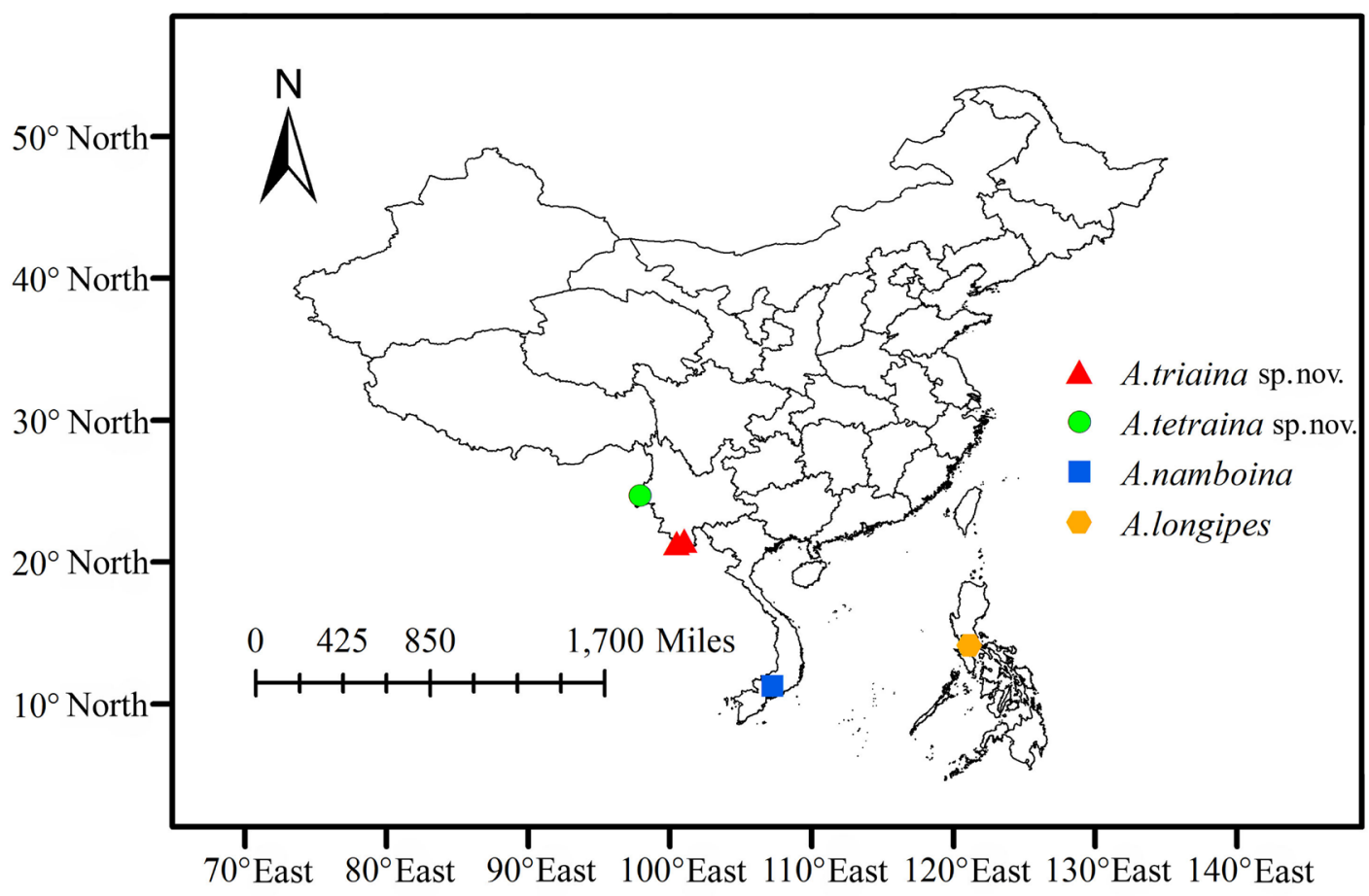

Fig. 35. Geographic distributions of species of Augilina Melichar, 1914. 


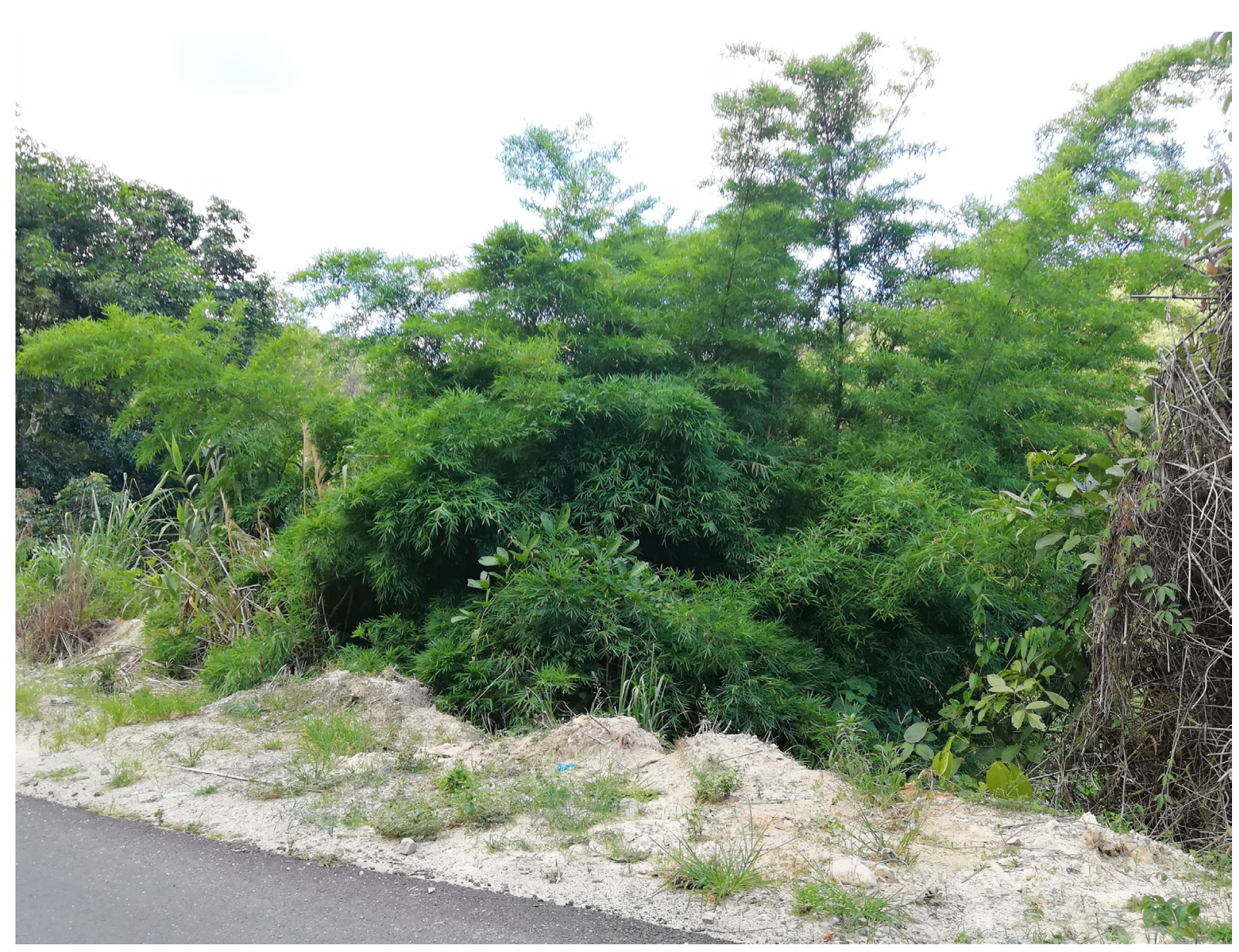

Fig. 36. The habitat of A. triaina Chen \& Gong sp. nov. (23 June 2019, Jinghong City). Photograph by Nian Gong.

\section{Host plant}

Our field survey showed that the new species of Augilina from Southwest China occur on bamboo. The habitat of $A$. triaina sp. nov. is shown in Fig. 36, unfortunately, no more specific information about the host bamboo species is available for A. tetraina sp. nov. According to Gnezdilov (2013b), A. namboina was also collected on bamboo. Therefore, we infer that the host plant of the genus Augilina is bamboo. From the information we have obtained, we can conclude that the genera Augilodes Fennah, 1963, Pseudosymplanella Che, Zhang \& Webb, 2009, Symplana Kirby, 1891, Symplanella Fennah, 1987 and Youtuus Chen \& Gong, 2018 of the tribe Augilini occur on bamboo.

\section{Distribution}

Based on the literature and the result of field work, A. longipes Melichar, 1914 was collected in the Philippines (Melichar 1914), A. namboina Gnezdilov, 2013 occurred in Vietnam (Gnezdilov 2013b), and the two new species described above are distributed in southern China (Fig. 35). It seems that the members of the genus Augilina are restricted to the Oriental region.

\section{Acknowledgments}

We are grateful to collectors for collecting specimens. This work was supported by the National Natural Science Foundation of China (No. 31472033, 32060343, 31601886), the Program of Excellent Innovation Talents, Guizhou Province (No. 20154021), the Science and Technology Program of Guizhou Province 
(No. Qiankehejichu [2018]1031), the Program of Scientific Research Foundation for Introduced Talent of Guizhou University (No. Guidarenjihezi (2017)18), and the Science and Technology Support Program of Guizhou Province (No. 20201Y129).

\section{References}

Bourgoin T., Wang R.R., Asche M., Hoch H., Soulier-Perkins A., Stroinski A., Yap S. \& Szwedo J. 2015. From micropterism to hyperpterism: recognition strategy and standardized homology-driven terminology of the forewing venation patterns in planthoppers (Hemiptera: Fulgoromorpha). Zoomorphology 134: 63-77. https://doi.org/10.1007/s00435-014-0243-6

Chan M.L. \& Yang C.T. 1994. Issidae of Taiwan (Homoptera: Fulgoroidea). Taichung, Taiwan.

Emeljanov A.F. 1999. Notes on delimitation of families of the Issidae group with description of a new species of Caliscelidae belonging to a new genus and tribe (Homoptera, Fulgoroidea). Zoosystematica Rossica 8 (1): 61-72.

Gnezdilov V.M. 2013a. Modern system of the family Caliscelidae Amyot et Serville (Homoptera, Fulgoroidea). Zoologichesky Zhurnal 92 (10): 1309-1311. [In Russian; English translation published in Entomological Review (2014) 94 (2): 211-214. https://doi.org/10.1134/S0013873814020092

Gnezdilov V.M. 2013b. A new species of the genus Augilina Melichar (Hemiptera, Fulgoroidea, Caliscelidae) from Southern Vietnam. Deutsche Entomologische Zeitschrift 60 (2): 171-177.

Melichar L. 1914. Neue Fulgoriden von den Philippinen: I. Theil. The Philippine Journal of Science 9 (3): 269-283.

Manuscript received: 17 June 2020

Manuscript accepted: 9 February 2021

Published on: 6 April 2021

Topic editor: Nesrine Akkari

Section editor: Christopher H. Dietrich

Desk editor: Radka Rosenbaumová

Printed versions of all papers are also deposited in the libraries of the institutes that are members of the EJT consortium: Muséum national d'histoire naturelle, Paris, France; Meise Botanic Garden, Belgium; Royal Museum for Central Africa, Tervuren, Belgium; Royal Belgian Institute of Natural Sciences, Brussels, Belgium; Natural History Museum of Denmark, Copenhagen, Denmark; Naturalis Biodiversity Center, Leiden, the Netherlands; Museo Nacional de Ciencias Naturales-CSIC, Madrid, Spain; Real Jardín Botánico de Madrid CSIC, Spain; Zoological Research Museum Alexander Koenig, Bonn, Germany; National Museum, Prague, Czech Republic. 